\title{
Equilibrium Sorption of Lead and Nickel from Solutions by Flame of the Forest (Delonix regia) Pods: Kinetics and Isothermic Study
}

\author{
Aiyesanmi Ademola Festus, Okoronkwo Afamefuna Elvis*, Akinmolayan Bolanle Morayo
}

Department of Chemistry, The Federal University of Technology, Akure, Nigeria.

Email: *afamex@yahoo.com

Received December $18^{\text {th }}, 2012$; revised January $17^{\text {th }}, 2013$; accepted February $21^{\text {st }}, 2013$

\begin{abstract}
Batch adsorption techniques were used to study the biosorption of Lead and Nickel from aqueous solutions by Flame of the forest pods. The effects of optimum $\mathrm{pH}$, contact time, metal ion concentration, biosorbent dose, biosorbent particle size and the presence of sodium, calcium and magnesium interfering ions on the sorption were investigated. Experimental results showed that Delonix regia biomass was effective in removing these metals from aqueous solutions as the equilibrium biosorption of both metals was attained within 60 minutes of interaction with $98 \%$ of the metals removed within this period. Sorption of these metals was dependent on $\mathrm{pH}$ as maximum removal was attained at $\mathrm{pH} 4$ and $\mathrm{pH} 5$ for Lead and Nickel ions respectively. Adsorption experiments showed that the process followed the pseudo second order kinetic model with high $\mathrm{r}^{2}$ (0.9999) and the equilibrium data fitted well with Langmuir and Freundlich isotherm models. The presence of competing ions impacted negatively on the sorption process irrespective of the type used. $27 \%$ and $36 \%$ of lead (II) were recovered from the spent biosorbents with $1 \mathrm{M} \mathrm{HCl}$ and disodium salt of EDTA solutions respectively.
\end{abstract}

Keywords: Equilibrium Sorption; Delonix regia; Lead; Nickel; Isotherms; Kinetics; Pseudo Second Order; Langmuir

\section{Introduction}

The presence of heavy metals over permissible levels in drinking water may cause adverse effects on human physiology. Metals such as $\mathrm{Pb}, \mathrm{Ni}, \mathrm{Cd}, \mathrm{Hg}, \mathrm{Cu}$ are known to be major anthropogenic pollutants in water with permissible limits for Lead and Nickel in drinking water being $0.01 \mathrm{mg} / \mathrm{L}$ and $0.02 \mathrm{mg} / \mathrm{L}$ respectively [1]. These metals may come from different sources such as electroplating, textile, smelting, mining, glass and ceramic industries as well as storage batteries, metal finishing, petroleum, fertilizer, pulp and paper industries [2,3]. Lead can cause several unwanted effects, including disruption of the biosynthesis of hemoglobin, anemia, rise in blood pressure, kidney damage, subtle abortions, birth defects, disruption of nervous systems, brain damage, decline fertility of men through sperm damage, diminished learning abilities of children, abdominal pains, adrenal insufficiency, blindness, cardiovascular disease, Liver dysfunction, and a host of others diseases [4-6]. Nickel also pose health hazard to certain individuals causing serious health problems including: anorexia, kidney dysfunction, apathy, disruption of hormone and lipid metabolism,

\footnotetext{
"Corresponding author.
}

muscle tremors, fever, intestinal cancer, heart attack, headache, nausea, oral cancer, skin problems and vomiting $[7,8]$. The use of conventional methods for the removal of heavy metal can be expensive, prohibitive for developing economics and most times do not work well for low concentration of the polluting metals [9-11], thus it becomes imperative to search for alternatives.

Biosorbents lately have become of considerable interest. The use of indigenous biodegradable resources for treating hazardous waste would be less expensive and more effective [12]. Various low cost adsorbents such as onion skin [13], tea leaves [14], Black Oak bark, Redwood bark, Chistosan, Rice hull, Zeolite, Bentonite, Xanthate, Sawdust, Formaldehyde-polymerised peanuts skins $[9,15]$ are known to adsorb heavy metal ions from solutions in their native state and with suitable chemical treatment, the adsorption capacity can be significantly enhanced [16]. The aim of this work is to investigate the adsoption capacity of Lead and Nickel from aqueous solutions by Flame of the Forest (Delonix regia) pods (Figure 1).

The Flame of the Forest (Delonix regia), a medium sized tree, growing from 20 - 40 feet high is a member of legume family which produces brown woody seed pods 


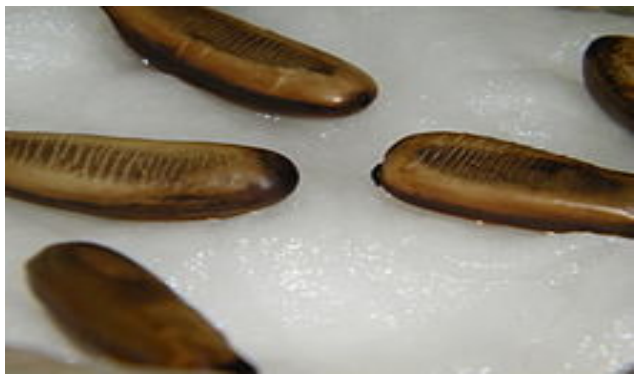

Figure 1. Matured Delonix regia pods.

that lengths up to $60 \mathrm{~cm}$ and $5 \mathrm{~cm}$ wide with trunk that is usually crooked and twisted with irregular braches and rough grey bark [17]. The effects of $\mathrm{pH}$, contact time, biosorbent dose, biosorbent particle size, adsorbate concentration and the presence of interfering ions were also studied.

\section{Materials and Methods}

Lead trioxonitrate (V) and Nickel chloride hexahydrate were used for the preparation of stock $\mathrm{Pb}$ (II) and $\mathrm{Ni}$ (II) solutions respectively. Calcium tetraoxosulphate (VI), magnesium tetraoxosulphate (VI) heptahydrate and sodium chloride were used for ionic strength study. The adjustment of $\mathrm{pH}$ was done with hydrochloric acid and ammonia solution where necessary. Desorption of adsorbed metal from the biomass was done with sodium salt of ethylene diamine tetraacetic acid and hydrochloric acid.

\subsection{Sorbent Preparation}

The matured dried pods of the biomass, Delonix regia were harvested in April (dry season period) from The Federal University of Technology, Akure. The dried biomass parts were thoroughly washed with distilled water, chopped into small pieces and oven dried at $90^{\circ} \mathrm{C}$ $105^{\circ} \mathrm{C}$ for three days, then it was grounded and milled to powdered form. The powder was sieved through a set of $2000 \mu \mathrm{m}, 1400 \mu \mathrm{m}, 1180 \mu \mathrm{m}$ and $850 \mu \mathrm{m}$ mesh sizes to obtain four different particle sizes to be used for subsequent experiments. All the different particle sizes were washed with $0.1 \mathrm{M} \mathrm{HCl}$ by vortexing and subsequent washing with distilled-deionized water was done several times until the $\mathrm{pH}$ of the wash water became virtually neutral.

\subsection{Sorption Experiments}

\subsubsection{Uptake Kinetics}

Determination of the optimum $\mathrm{pH}$ for biosorption is paramount to the success of further investigation. From the prepared biomass, $10 \mathrm{mg} / \mathrm{mL}$ suspension was made in designated glass beakers and stirred to give a homoge- neous mixture. The suspensions in these beakers were adjusted to $\mathrm{pH}$ values $1-6$, each was equilibrated for 15 minutes, centrifuged at $760 \mathrm{rpm}$ for 5 minutes and the supernatants discarded. $50 \mathrm{ml}$ of individual metal solutions of $100 \mathrm{ppm}$ were added, stirred and allowed to stay. Contacting and stirring were done for 6 hours after which the suspensions were filtered, the filtrates were then transferred to clean sample bottles for metal analysis. All other batch experiments were then conducted at $\mathrm{pH} 4$ for $\mathrm{Pb}$ and 5.0 for $\mathrm{Ni}$ as their observed optimum $\mathrm{pH}$ respectively. The influence of various experimental parameters such as contact time, initial concentration of metal ion, ionic strength, mass of Delonix regia used and particle size on the kinetics of $\mathrm{Pb}$ and $\mathrm{Ni}$ removal was studied in order to optimize the process.

The initial solutions concentration of $100 \mathrm{ppm}$ for both metals was used for all experiments except for that carried out to examine the effect of initial concentration of the metals. In order to study the metal-removal kinetics, $0.5 \mathrm{~g}$ of Delonix regia was contacted with $50 \mathrm{ml}$ of metal solution agitated vigorously. At the appropriate time intervals $(5,15,30,60,90,120,180,240,300$ and 360 $\mathrm{min}$ ), the solutions were filtered and analyzed to determine residual metal concentration in aqueous solutions.

\subsubsection{Uptake Isotherm}

The equilibrium isotherms were determined by contacting constant mass $(0.50 \mathrm{~g})$ of the biosorbent with $50 \mathrm{ml}$ metal solutions of different concentration (10, 20, 40, $100,200 \mathrm{ppm})$. Aliquots were taken from the suspensions and transferred to clean tubes at the optimum time and subsequently analyzed for metal content.

The study of effect of ionic strength on the metal removal, sodium, calcium, and magnesium ions at different concentrations $(50,100,200,300,500,750$ and 1000 ppm) was carried out.

\subsection{Desorption Studies}

Recovery of lead and nickel ions adsorbed on the biosorbent was done with different concentrations $(0.1,0.5$, 0.75 and $1.0 \mathrm{M}$ ) of hydrochloric acid and disodium salt of ethylenediamine tetraacetic acid. The desired volume of $50 \mathrm{ml}$ of $200 \mathrm{ppm}$ of metal solution of adjusted $\mathrm{pH}$ was poured into designated beakers for each concentration of desorbing agents. These metal solutions were contacted with $0.5 \mathrm{~g}$ of the biomass for the optimum contact time after which they were filtered, the filtrate was discarded and the spent biomass were contacted with the appropriate concentration of the desorbing agent for the optimum contact time; at the end of which the contents were filtered and the filtrates collected were analyzed for metal content. 


\section{Results and Discussion}

\section{1. pH Profile Studies}

The effects of $\mathrm{pH}$ on $\mathrm{Pb}$ and $\mathrm{Ni}$ ions adsorption by the dried pods of flame of the forest is presented in Figure 2. The results show that the biosorption of $\mathrm{Pb}$ (II) and $\mathrm{Ni}$ (II) is $\mathrm{pH}$ dependent, increasing gradually from 1.0 to 4.0 for lead and from 1.0 to 5.0 for nickel. Maximum percentage adsorption of $99 \%$ was observed at $\mathrm{pH} 4.0$ for lead, the sorption reduced to about $96 \%$ at the $\mathrm{pH}$ of 4.8 .

Nickel attained maximum sorption at $\mathrm{pH} 5.0$, as the percentage uptake increased from $86 \%$ at $\mathrm{pH} 1.0$ to $98 \%$

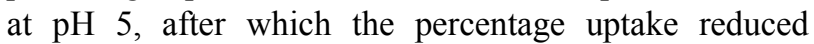
gradually. One reason for the low adsorption of metals at lower $\mathrm{pH}$ is due to the increased availability of hydrogen ions which are known to compete with metal ions for binding sites on the biosorbent [18]. The adsorption process is limited considerably by precipitation of most heavy metal ions which occur at $\mathrm{pH}$ greater than 6 [19].

\subsection{Effect of Contact Time}

The uptake of lead and nickel ions by the biosorbent at different contact times is shown in Figure 3.

An ideal biosorbent should rapidly adsorb high concentration of the heavy metals; this is evident from the result of the study conducted using Delonix regia biomass. Sorption of $\mathrm{Pb}^{2+}$ and $\mathrm{Ni}^{2+}$ by this biomass was very rapid with about $95 \% \mathrm{Ni}^{2+}$ and $>95 \% \mathrm{~Pb}$ uptake within the first five (5) minutes of interaction. This notwithstanding, contact times of up to 360 minutes were investigated. Sorption of lead ions was relatively the same after 60 minutes of contact time. It was observed that $\mathrm{Ni}$ sorption was increased to $98.76 \%$ at 60 minutes contact time, thereafter intermittently increasing and decreasing due to desorption and re-adsorption of the sorbate ions [20].

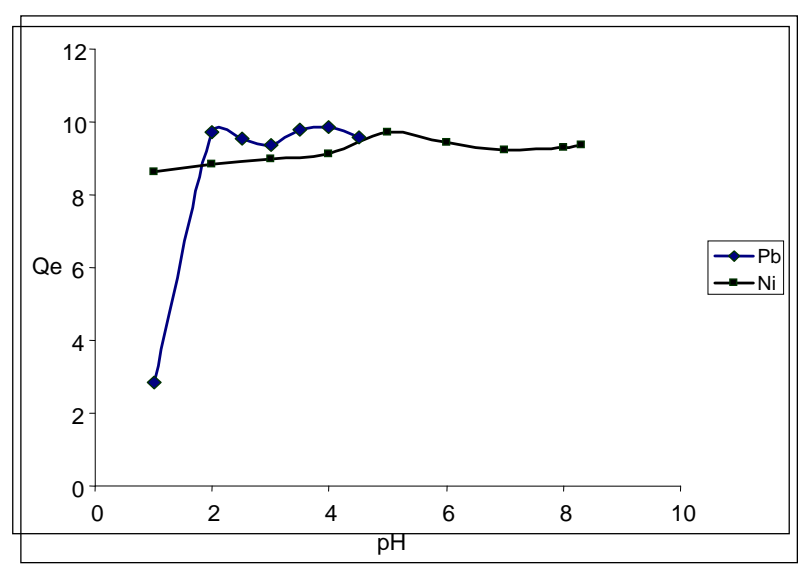

Figure 2. $\mathrm{pH}$ profile studies of the biosorption of $\mathrm{Pb}^{2+}$ and $\mathrm{Ni}^{2+}$.

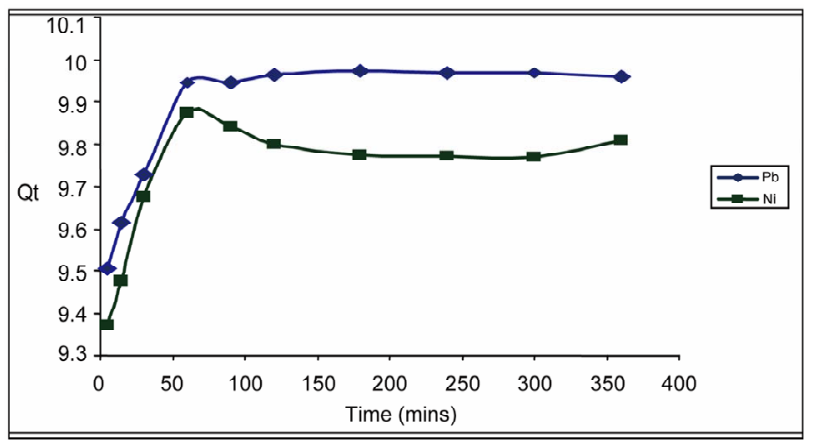

Figure 3. Time dependence studies of the biosorption of $\mathrm{Pb}^{2+}$ and $\mathrm{Ni}^{2+}$.

\subsection{Kinetics of Lead and Nickel Sorption}

The kinetics of the biosorption data were evaluated using pseudo first order, second order kinetic, Elovich and Intra particle diffusion models.

According to [21], the Lagergren pseudo first order model is given as Equation (1):

$$
\mathrm{Qt}=\mathrm{Qe}\left[1-\exp \left(\mathrm{K}_{1} \mathrm{t}\right)\right]
$$

The integrated form of the first order equation is given as Equation (2):

$$
\log (\mathrm{Qe}-\mathrm{Q} \mathrm{t})=\log \left(\mathrm{Qe}-\mathrm{K}_{1} \mathrm{t}\right) / 2.303
$$

where Qe and Qt are the amount of metal adsorbed per unit weight of biosorbent at equilibrium and at any time $t$ respectively $(\mathrm{mg} / \mathrm{g}), \mathrm{K}_{1}$ is the rate constant of pseudo first order sorption $\left(\mathrm{min}^{-1}\right)$. The rate constant for the first order reaction can be obtained from the slope of the plot of $\log (\mathrm{Qe}-\mathrm{Qt})$ versus time ( $\mathrm{t})$. Linear plots having high values of coefficient of correlation $\left(\mathrm{R}^{2}\right)$ show that this kinetic model is applicable. From Table $\mathbf{1}$ and Figure 4 , it is observed that the rate constant and coefficient of correlation were negative, thus the biosorption of both metal ions by flame of the forest biomass were not well fitted to pseudo first order kinetic model.

The pseudo second order kinetic model equation given as:

$$
\mathrm{Qt}=\mathrm{Qe}\left(\mathrm{QeK}_{2} \mathrm{t} / 1+\mathrm{QeK}_{2} \mathrm{t}\right)
$$

The linearized form is:

$$
\mathrm{t} / \mathrm{Qt}=1 / \mathrm{K}_{2}+\mathrm{t} / \mathrm{Qe}
$$

where $\mathrm{K}_{2}\left(\mathrm{gmg}^{-1} \cdot \mathrm{min}^{-1}\right)$ is the second order rate constant for the sorption, Qe and Qt are the amount of biosorbent at equilibrium and at any time $\mathrm{t}$, respectively $(\mathrm{mg} / \mathrm{g})$.

$\mathrm{Qe}$ is derivable from the plot of $\mathrm{t} / \mathrm{Qt}$ versus $\mathrm{t}$.

The main assumption of pseudo second order kinetic model is that the rate limiting steps may be chemical sorption involving forces through exchange or sharing of electrons between the metal ions and the biomass [22]. 
Table 1. Kinetic parameters for metal sorption onto Delonix regia.

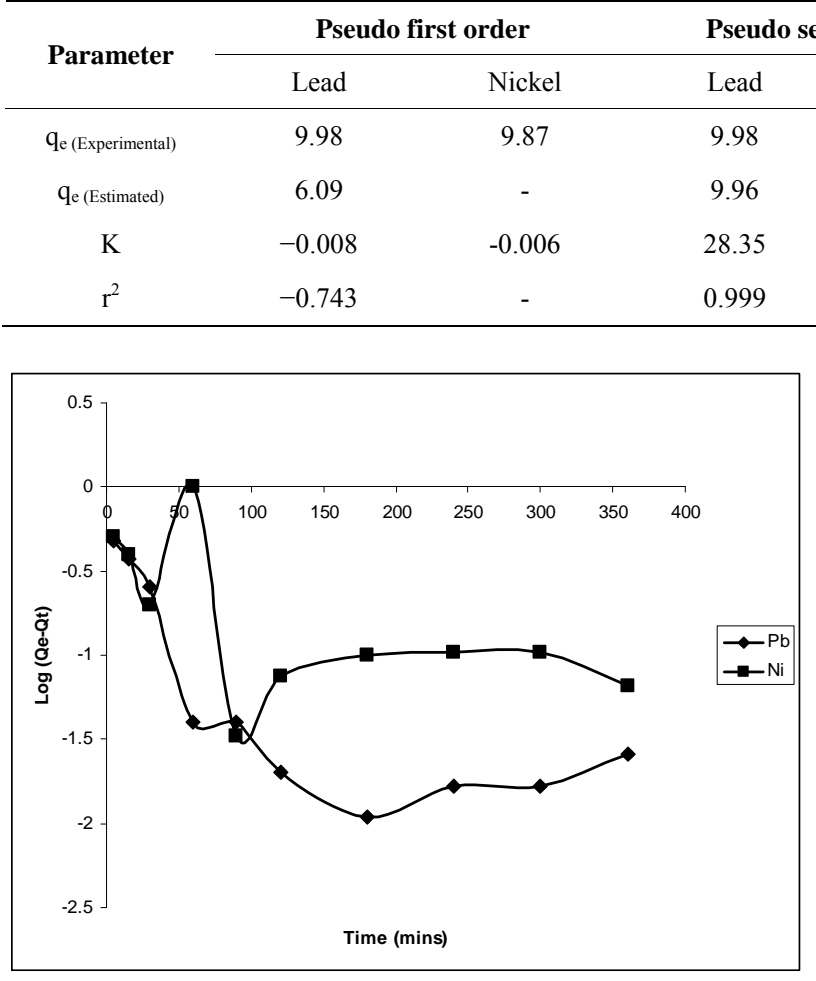

Figure 4. First order kinetics of the biosorption of $\mathrm{Pb}^{2+}$ and $\mathrm{Ni}^{2+}$.

From Table 1 and Figure 5, it is evident that kinetics of sorption for $\mathrm{Pb}^{2+}$ and $\mathrm{Ni}^{2+}$ by Delonix regia with high correlation coefficient followed Lagergren second order kinetic model. The estimated Sorption Capacity Qe of $9.82 \mathrm{mg} / \mathrm{L}$ for $\mathrm{Ni}^{2+}$ tallied with the obtained value of 9.88 $\mathrm{mg} / \mathrm{L}$. Sorption Capacity of $\mathrm{Pb}^{2+}$ was $9.99 \mathrm{mg} / \mathrm{L}$ as against the Second Order estimation of $9.97 \mathrm{mg} / \mathrm{L}$.

The Elovich model equation is another rate equation based on the biosorption capacity of biosorbents. It is generally expressed as:

$$
\frac{\mathrm{dQt}}{\mathrm{dt}}=\propto \mathrm{e}^{-\beta \mathrm{Qt}}
$$

where $\alpha$ is the initial adsorption rate $\mathrm{mg} \cdot \mathrm{g}^{-1} \cdot \mathrm{min}^{-1}, \beta$ is the adsorption constant in $\mathrm{g} \cdot \mathrm{mg}^{-1}$ during any one experiment.

The Integrated form is represented as:

$$
\mathrm{Qt}=\left(\frac{2.3}{\beta}\right) \cdot \log \left(\mathrm{t}+\frac{1}{\alpha \beta}\right)-\left(\frac{2.3}{\beta}\right)-\log \left(\frac{1}{\alpha}-\beta\right)
$$

The Elovich equation is simplified by Chien and Clayton in 1980 by assuming that $\alpha \beta \gg 1$ and by applying boundary conditions of $\mathrm{Q}=0$ at $\mathrm{t}=0$ and $\mathrm{Q}=\mathrm{Q}$ at $\mathrm{t}=\mathrm{t}$, then, the integrated form of the Elovich equation becomes:

$$
\mathrm{Qt}=\propto \ln (\beta \alpha)+\propto \ln (\mathrm{t})
$$

The Elovich kinetic constants $(\alpha$ and $\beta$ ) could be deduced from the slope and intercept of the linear plots of Qt against $\ln (\mathrm{t})$. From Table 1 and Figure 6, it can be deduced that sorption of $\mathrm{Pb}^{2+}$ and $\mathrm{Ni}^{2+}$ by Delonix regia can be predicted with Elovich kinetic model with coefficient of correlation factor of 0.873 for $\mathrm{Pb}^{2+}$ and 0.689 for $\mathrm{Ni}^{2+}$. These values however are not very good fit compared to the 0.999 obtained from the pseudo second order model.

\subsection{Intra Particle Diffusion}

Contributions of intra particle diffusion mechanism were also examined using the Weber and Moris equation [22].

$$
\mathrm{Qt}=\mathrm{K}_{1} d \mathrm{t}^{1 / 2}
$$

$\mathrm{Ki} d$ is the intra-particle diffusion rate constant $\left(\mathrm{mg} \cdot \mathrm{min}^{-1 / 2} \cdot \mathrm{g}^{-1}\right)$, and Qt is the amount of solute adsorbed $(\mathrm{mg} / \mathrm{g})$ at any time, $\left(\mathrm{min}^{-1}\right)$.

According to the equation for intra particle diffusion mechanism, the plot of Qt versus $t^{1 / 2}$ should be linear if intra-particle diffusion is the only mechanism applicable. Figure 7 shows that for both $\mathrm{Pb}^{2+}$ and $\mathrm{Ni}^{2+}$, the plots are not linear and do not pass through the origin implying that intra particle diffusion mechanism is not the only mechanism involved in the sorption of $\mathrm{Pb}^{2+}$ and $\mathrm{Ni}^{2+}$. It can be deduced therefore that the sorption of both metals by Delonix regia involve both physisorption and chemisorption Processes.

\subsection{Effects of Metal Ion Concentration on Sorption Process}

Sorption of heavy metal ions by flame of the forest biosorbent depended largely on the initial concentration of metal ions in the solution. The effect of different concentrations of the metal ions on the biosorption process is shown in Figure 8. It was observed that for both lead and nickel the total amount of metal ions removed increased with increasing concentration but the percentage removal per gram of biosorbent was reduced.

When 20 ppm of metal ions was used, adsorption ca- 


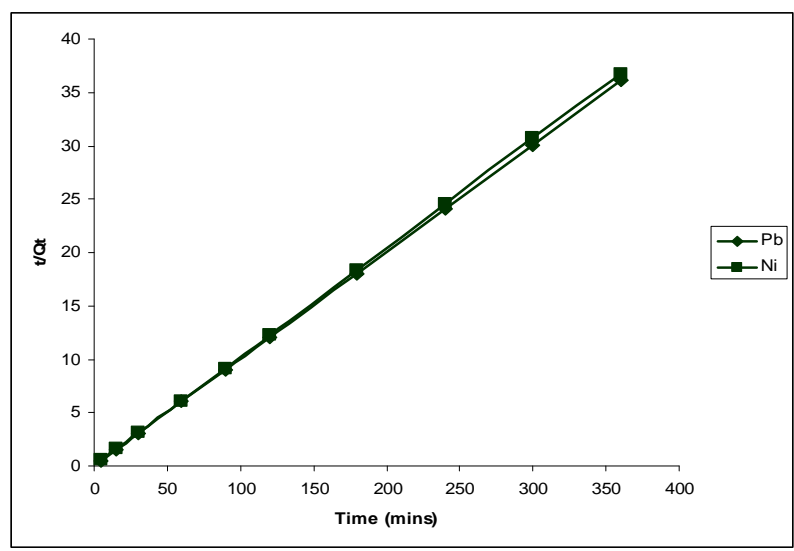

Figure 5. Second order kinetics of the biosorption of $\mathbf{P b}^{2+}$ and $\mathrm{Ni}^{2+}$.

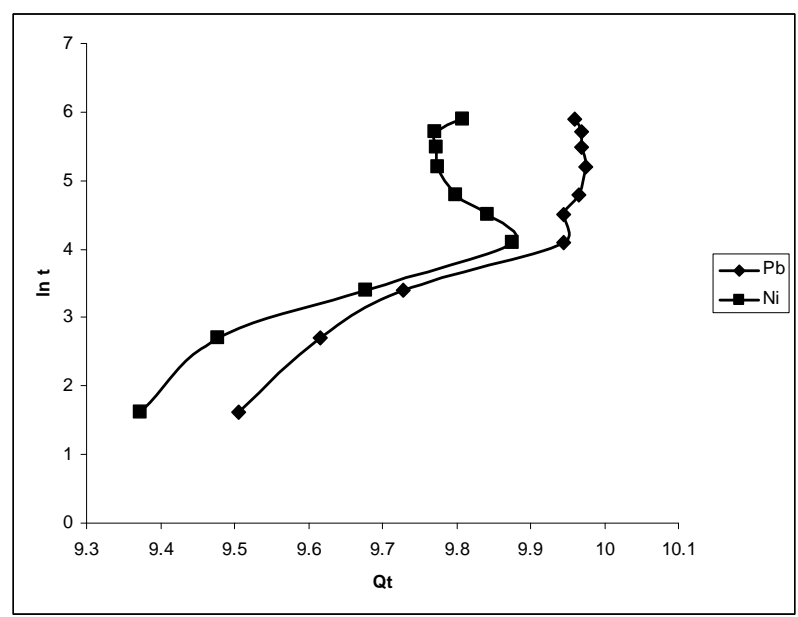

Figure 6. Plot of elovich model of the biosorption of $\mathbf{P b}^{2+}$ and $\mathrm{Ni}^{2+}$.

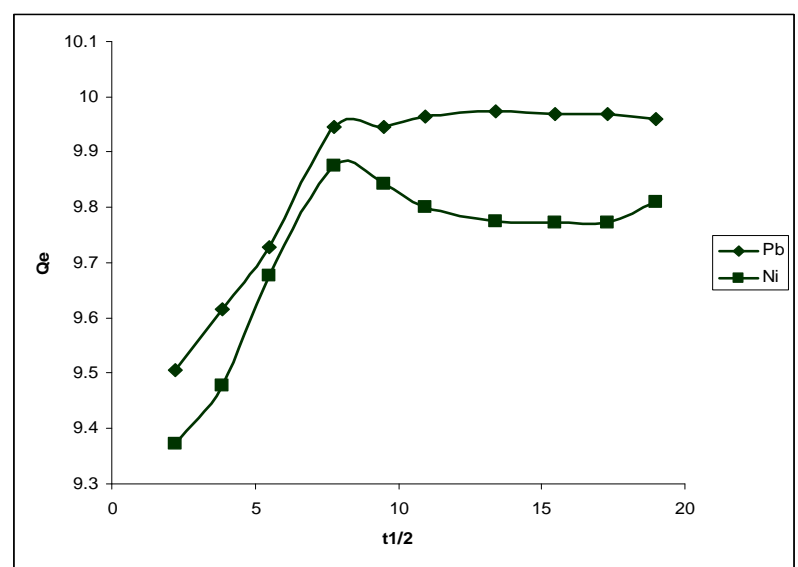

Figure 7. Intra-particle diffusion of the biosorption of $\mathbf{P b}^{2+}$ and $\mathrm{Ni}^{2+}$.

pacity of 1.984 and 1.978 were recorded for $\mathrm{Pb}^{2+}$ and $\mathrm{Ni}^{2+}$ respectively, at $80 \mathrm{ppm} ; 7.88$ and 7.89 were obtained

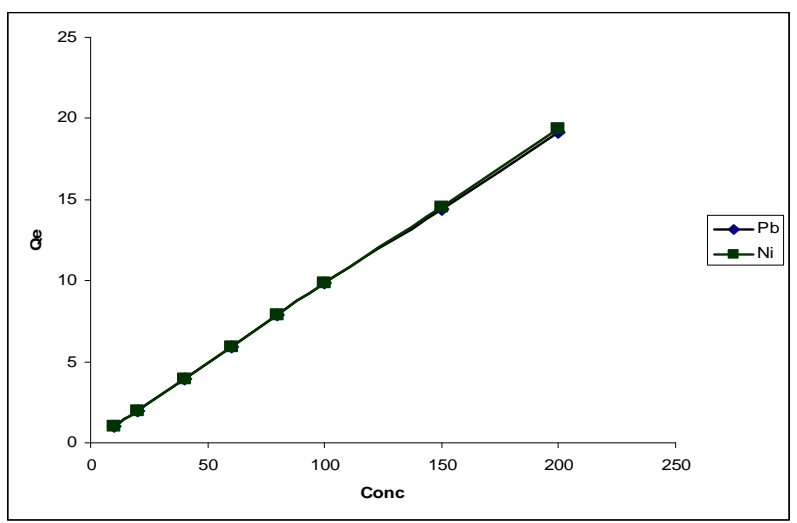

Figure 8. Concentration studies of the biosorption of $\mathbf{P b}^{2+}$ and $\mathrm{Ni}^{2+}$.

and at 100 ppm; 9.84 and 9.87 were obtained. At higher concentrations, more lead and nickel ions were left unadsorbed in solution due to the saturation of binding sites. This appears to be due to the increase in the number of ions competing for the available binding sites in the biomass [23].

\subsection{Sorption Isotherms}

The Langmuir, Freundlich and Temkin models were used to describe adsorption isotherms and are presented in Figures 9-11 respectively. It can be deduced from Table 2 that the adsorption process of flame of the forest pods for the metals investigated followed both the Langmuir and Freundlich models. Although the Freundlich model with a higher $\mathrm{R}^{2}(0.99)$ for both metals is better to explain the process.

Langmuir's model which is valid for monolayer adsorption onto a surface containing equivalent sites is based on the assumption that maximum adsorption corresponds to a saturated monolayer of solution molecules on the adsorbent surface. On the basis of this assumption, the Langmuir equation can be expressed as:

$$
\frac{\mathrm{Ce}}{\mathrm{Qe}}=\frac{1}{\mathrm{Qo}} \mathrm{b}+\frac{\mathrm{Ce}}{\mathrm{Qo}}
$$

where Qo and b, the Langmuir constants are adsorption capacity and adsorption energy respectively, Qe is the amount of adsorbate adsorbed per unit weight of biosorbent and $\mathrm{Ce}$ is the metal final concentration in the solution.

Freundlich preposition of multilayer adsorption is represented as Equation (10)

$$
\operatorname{LogQe}=\operatorname{LogKf}+1 / n \operatorname{LogCe}
$$

where $\mathrm{n}$ and $\mathrm{Kf}$ are constants related to adsorption efficiency and adsorption capacity respectively; Qe is amount of adsorbate adsorbed per unit weight of biosorbent and 
Table 2. Isotherms model parameters estimated for $\mathrm{Pb}(\mathrm{II})$ and $\mathrm{Ni}(\mathrm{II})$ ion sorption.

\begin{tabular}{cccc}
\hline Model & Parameter & Lead & Nickel \\
\hline \multirow{3}{*}{ Freundlich } & $\mathrm{K}_{\mathrm{f}}(\mathrm{mg} / \mathrm{g})\left(\mathrm{dm}^{3} / \mathrm{mg}\right)^{1 / \mathrm{n}}$ & 6.24 & 6.10 \\
& $\mathrm{n}^{\mathrm{f}}$ & 4.70 & 3.14 \\
& $\mathrm{r}^{2}$ & 0.988 & 0.986 \\
Langmuir & $\mathrm{Q}_{\max }(\mathrm{mg} / \mathrm{g})$ & 8.33 & 9.98 \\
& $\mathrm{~b}\left(\mathrm{dm}^{3} / \mathrm{mg}\right)$ & 0.082 & 0.099 \\
& $\mathrm{r}^{2}$ & 0.985 & 0.973 \\
Temkin & $\mathrm{a}$ & 0.257 & 0.218 \\
& $\mathrm{~b}$ & -2.239 & -1.876 \\
\hline
\end{tabular}

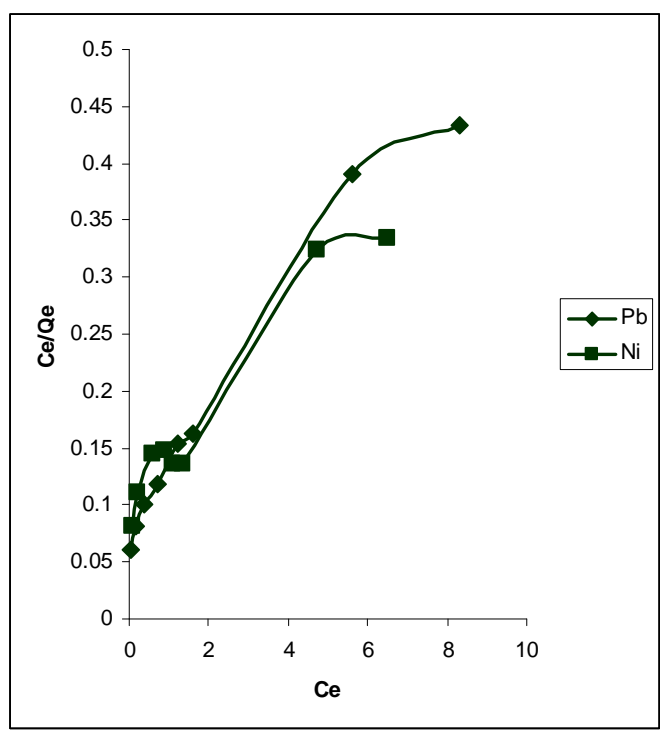

Figure 9. Langmuir isotherm of the biosorption of $\mathbf{P b}^{2+}$ and $\mathrm{Ni}^{2+}$.

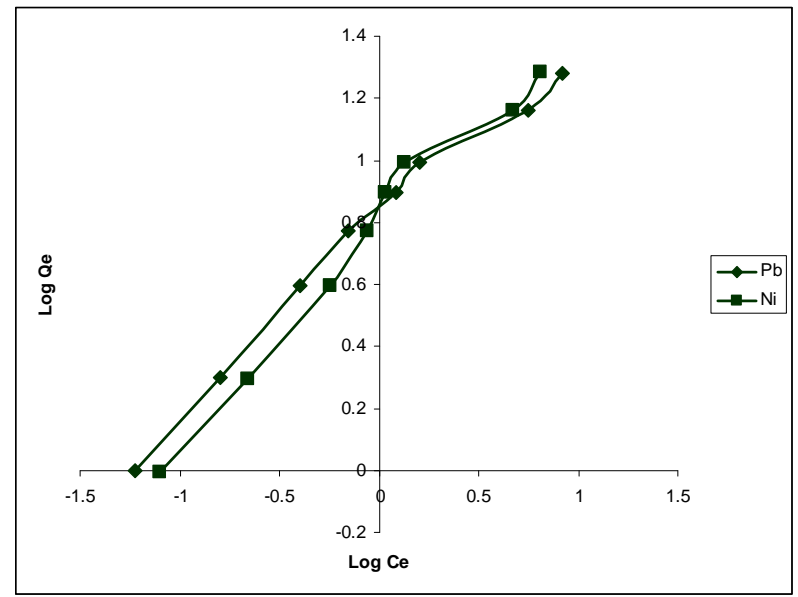

Figure 10. Freundlich isotherm of the biosorption of $\mathbf{P b}^{2+}$ and $\mathrm{Ni}^{2+}$.

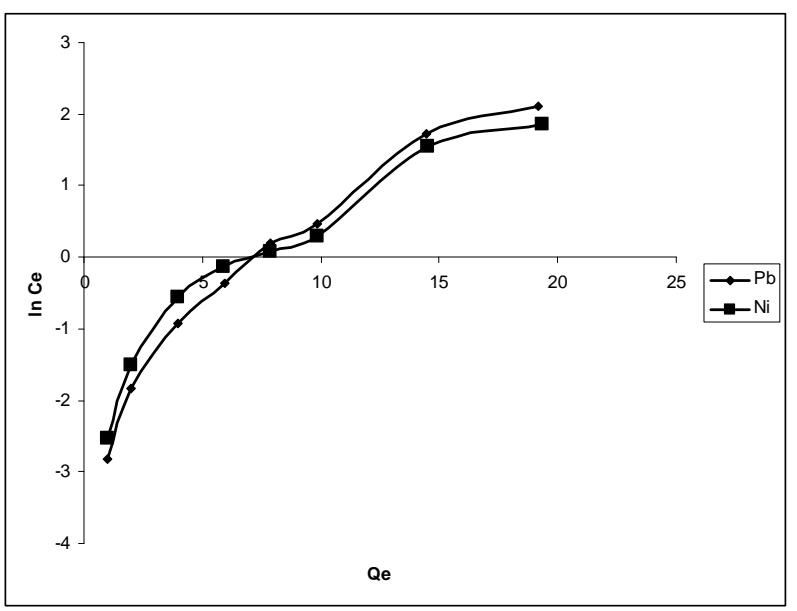

Figure 11. Plot of temkin isotherm model of the biosorption of $\mathrm{Pb}^{2+}$ and $\mathrm{Ni}^{2+}$.

$\mathrm{Ce}$ is the final metal concentration in the solution.

The Temkin isotherm model given by Equation (11) takes into account the indirect adsorbate-adsorbate interactions on adsorption isotherms.

$$
\mathrm{Qe}=\mathrm{a}+\mathrm{b} \ln \mathrm{C}
$$

where $\mathrm{C}=$ Concentration of adsorbate in solution at equilibrium (mg/L).

Qe $=$ Amount of metal adsorbed per unit weight of adsorbent $(\mathrm{mg} / \mathrm{g})$, $\mathrm{a}$ and $\mathrm{b}$ are constants related to adsorption capacity and intensity of adsorption which can be calculated from the plots of Qe against $\ln \mathrm{C}$.

In indirect interactions, the adsorbate changes the surface around the adsorbed sites, which in turn affects the adsorption of other adsorbate molecules nearby.

\subsection{Effect of Biosorbent Dose and Particle Size}

Biosorbent dose is an important parameter because it determines the capacity of the adsorbate. The amount of 
lead and nickel ions adsorbed by the biomass increased by increasing the dose of biosorbent from $0.25 \mathrm{~g}$ to $1.5 \mathrm{~g}$; the adsorption capacity of the biosorbent increased from 9.04 to 9.973 for $\mathrm{Pb}^{2+}$ and from 9.68 to 9.92 for $\mathrm{Ni}^{2+}$. Though the total metal uptake increased with the increased dose of biosorbent, the metal uptake per gram of biosorbent had been drastically decreased due to the interference of inter-particle cohesive forces and interference of binding site [24].

Study carried out using Delonix regia of different particle sizes $(850,1180,1400$ and $2000 \mu \mathrm{m})$ showed that milling the biosorbent to a particle size of $850 \mu \mathrm{m}$ would be most suitable for the biosorption process. The removal of the metal ions increased with a decrease in particle size, probably because of the larger surface area available. The mechanism of the metal ions uptake is one of adsorption onto the external sites of a non-porous adsorbent [25].

\subsection{Interference Study}

The sorption of metal ions in the presence of other common ions may be affected due to competition for the sorption sites [26]. For the determination of any interference caused by other cations on the biosorption of lead and nickel ions by the biomass, calcium, magnesium and sodium ions were used as ionic medium, the effect of the cations on the metal uptake are demonstrated in Figure 12. The results show a reduction in the uptake of lead and nickel ions by the biomass in the presence of each of the cations used. Lead which, without interference recorded $98 \%$ adsorption to Delonix regia biomass was reduced to $89 \%, 85 \%$ and $78 \%$ with $200 \mathrm{ppm}$ calcium, magnesium and sodium ions respectively. Similarly, a negative impact was observed for nickel as its removal was reduced from $97 \%$ to 85,84 and 89 percent by each

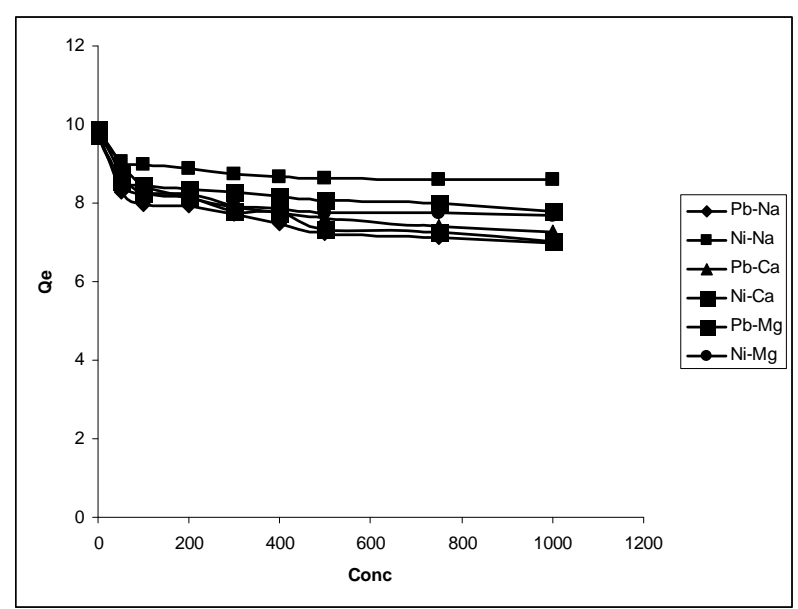

Figure 12. Interference studies of the biosorption of $\mathbf{P b}^{2+}$ and $\mathrm{Ni}^{2+}$. of these cations at the same concentration of interfering ions as used for lead. Reduction in metal removal percentage due to the increase of sodium ions was attributed to presence of competing ions for metal binding [27]. The decrease observed with calcium and magnesium however can be explained on the basis of the abundant $\mathrm{SO}_{4}^{2-}$ ions from the calcium tetraoxosulphate (VI) and magnesium tetraoxosulphate (VI). These ions could easily attach to the lead and nickel free ions hence reducing the available metal ions for adsorption to the biosorbent.

\subsection{Adsorption Capacity}

In order to establish the capacity of the biosorbent for the uptake of $\mathrm{Ni}^{2+}$ and $\mathrm{Pb}^{2+}$ an adsorption capacity experiment was conducted in a ten cycle mode. In the first cycle, $\mathrm{Pb}(\mathrm{II})$ ions adsorbed were about $95 \%$, but the percentage bound gradually reduced from the 1 st cycle as should be expected and at the 10th cycle about $70 \%$ of $\mathrm{Pb}$ (II) ions were adsorbed.

Likewise at the first cycle, $98 \%$ of $\mathrm{Ni}(\mathrm{II})$ ions were adsorbed, whereas at the 10th cycle about $94 \%$ of Ni(II) was bound to the biomass. As the binding sites get filled up, the amount of metal bound decreased. It should be noted that the fact that this biomass could remove as much as $70 \%$ of lead and $94 \%$ of nickel is an indicator of its viability as a good source of material for water treatment purposes. Considering the results obtained from this study, it is evident that the flame of the forest biomass could take more cycles of the metal ions and still be very viable.

\subsection{Desorption Study}

To make the adsorption process more economical, it is necessary to regenerate the spent biosorbent. The desorption and regeneration for $\mathrm{Pb}^{2+}$ and $\mathrm{Ni}^{2+}$ was done with different concentrations of sodium salt of EDTA and $\mathrm{HCl}$ (Tables 3). From the results it was observed that the percentage of $\mathrm{Pb}$ recovered with $0.1 \mathrm{M} \mathrm{HCl}$ was only $22.19 \%$ while $27.12 \% \mathrm{~Pb}$ was desorbed by $1 \mathrm{M} \mathrm{HCl}$.

With $0.1 \mathrm{M}$ disodium salt of EDTA, 27.79\% of $\mathrm{Pb}$ was recovered while $1 \mathrm{M}$ was able to recover $35.8 \%$. For Ni

Table 3. Desorption of adsorbed metals from Delonix regia using $1 \mathrm{M} \mathrm{HCl}$ and $0.1 \mathrm{M}$ EDTA.

\begin{tabular}{ccccc}
\hline HCl & \multicolumn{3}{c}{ EDTA } \\
\hline \multirow{2}{*}{ Conc (M) } & \multicolumn{2}{c}{ Percentage } & \multicolumn{2}{c}{ Recovery (\%) } \\
\cline { 2 - 5 } & Pb & Ni & Pb & Ni \\
\hline 0.10 & 22.19 & 7.00 & 27.79 & 6.30 \\
0.50 & 26.04 & 8.18 & 30.82 & 7.51 \\
0.75 & 26.14 & 9.10 & 33.23 & 8.67 \\
1.00 & 27.12 & 9.70 & 35.80 & 11.73 \\
\hline
\end{tabular}


the percentage metal recovered was $7.0 \%$ and $1 \mathrm{M}$ desorbed $9.7 \%$. Using $0.1 \mathrm{M}$ EDTA sodium salt of, $6.3 \%$ was desorbed while $1 \mathrm{M}$ desorbed $11.75 \%$ were desorbed with disodium salt of EDTA thus shows that the bond responsible for the biosorption process is not only physical adsorption but chemical sorption of the metal ions $(\mathrm{Pb}$ and $\mathrm{Ni})$ onto the biosorbent binding sites. These results are in agreement with what was earlier reported by [28]; where wheat bran was used for the removal of $\mathrm{Pb}$ (II) from wastewater.

\section{Conclusion}

The result of this investigation has shown that Delonix regia biosorbent has a great potential for the removal of lead and nickel from contaminated water. The biosorption of both metals on the adsorbent was rapid as over $90 \%$ of the metals were removed within the first $5 \mathrm{mi}-$ nutes of interaction and was found to follow pseudo-second order kinetic model. It was observed that the biosorption which fitted better to the Freundlich Isotherm model strongly depends on parameters such as $\mathrm{pH}$ of the solution, contact time, initial concentration of the metal ions, biosorbent dose and particle size. The presence of sodium, magnesium and calcium interfering ions reduced the binding efficiency of lead and nickel especially at higher concentration of these interfering ions. The result obtained from the desorption study show that the adsorption process could be both physisorption and chemisorption Processes.

\section{REFERENCES}

[1] WHO, "Guidelines for Drinking Water Quality," 3rd Edition, World Health Organization, Geneva, 2000.

[2] S. S Ahluwalia and D. Goyal, "Microbial and Plant Derived Biomass for Removal of Heavy Metal from Waste Water," Bioresource Technology, Vol. 98, No. 12, 2007, pp. 2243-2257. doi:10.1016/j.biortech.2005.12.006

[3] Z. Aksu, "Equilibrium \& Kinetic Modeling of Cadmium (II) Biosorption by C. vulgaris in a Batch System: Effect of Temperature," Separation and Purification Technology, Vol. 21, No. 3, 2001, pp. 285-294. doi:10.1016/S1383-5866(00)00212-4

[4] J. M. S. Pearce, "Burton's Line in Lead Poisoning," European Neurology, Vol. 57, No. 2, 2007, pp. 118-119. doi:10.1159/000098100

[5] B. Volesky, "Removal of Lead from Aqueous Solution by Penicillium Biomass," Biotechnology and Bioengineering, Vol. 42, No. 6, 1993, pp. 785-787. doi:10.1002/bit.260420615

[6] I. Gaballah and G. Kilbertus, "Recovery of Heavy Metal Ions through Decontamination of Synthetic Solutions and Industrial Effluents Using Modified Barks," Journal of Geochemical Exploration, Vol. 63, No. 1-3, 1998, pp. 21-
286.

[7] J. L. Gardea-Torresdey, J. R. Peralta-Videa, C. D. Rosa and J. G. Parsons, "Phytoremedition of Heavy Metals and Study of the Metal Coordination by x-Ray Absorption Spectroscopy," Coordination Chemistry Reviews, Vol. 249, No. 17-18, 2005, pp. 1797-1810. doi:10.1016/j.ccr.2005.01.001

[8] B. Volesky, "Biosorption of Heavy Metal," CRC Press, Boca Raton, 1990, p. 396.

[9] S. E. Bailey, J. J. Olin, R. M. Bricka and D. D. Adrian, "A Review of Potentially Low Cost Sorbents for Heavy Metals," Water Research, Vol. 33, No. 11, 1999, pp. 24692479. doi:10.1016/S0043-1354(98)00475-8

[10] J. Chang, R. Law and C. Chang, "Biosorption of Lead, Copper and Cadmium by Biomass of Pseudomonas acruginosa," Water Research, Vol. 31, No. 7, 1997, pp. 1651-1658. doi:10.1016/S0043-1354(97)00008-0

[11] E. S. Z. El-Ashtoukly, N. K. Amin and O. Abdelwahab, "Removal of Lead (II) and Copper (II) from Aqueous Solution Using Pomegranate Peel as a New Adsorbent," Desalination, Vol. 223, No. 1-3, 2008, pp. 162-173.

[12] M. N. V. Prasad and H. Freitas, "Removal of Toxic Metals from Solution by Leaf, Stem and Root Phytomass of Quercus ilex L. (Holl Oak)," Environmental Pollution, Vol. 110, No. 2, 2000, pp. 277-283. doi:10.1016/S0269-7491(99)00306-1

[13] P. Kumar and S. Daras, "Binding Heavy Metal Ions with Polymerized Onion Skin," Journal of Polymer Science Part A: Polymer Chemistry, Vol. 19, No. 2, 1981, pp. 397-402. doi:10.1002/pol.1981.170190216

[14] Y. Orhan and H. Buyukgungor, "The Removal of Heavy Metals by Using Agricultural Waste," Water Science and Technology, Vol. 28, No. 2, 1993, pp. 247-255.

[15] N. T. Abdel-Ghani, M. Hefry and G. A. F. El-Chaghaby, "Removal of Lead from Aqueous Solution Using Low Cost Abundantly Available Adsorbent," International Journal of Environmental Science and Technology, Vol. 4 No. 1, 2007, pp. 67-73.

[16] C. Raji and T. S. Anirudhan, "Kinetics of Pb(II) Adsorption by Polyacrylamide Grafted Sawdust," Indian Journal of Chemical Technology, Vol. 4, No. 3, 1997, pp. 157162.

[17] D. V. Cowen, "Flowering Trees and Shrubs in India," 6th Edition, Thacker \& Co., Bombay, 1984, p. 1.

[18] K. S. Low and C. S. Lee, "Sorption of Cadmium and Lead from Aqueous Solution by Spent Grain," Process Biochemistry, Vol. 36, No. 1-2, 2000, pp. 59-64. doi:10.1016/S0032-9592(00)00177-1

[19] K. Wang and B. Xing, "Adsorption and Desorption of Cadmium by Goethite Pretreated with Phosphate," Chemosphere, Vol. 48, No. 7, 2002, pp. 665-670. doi:10.1016/S0045-6535(02)00167-4

[20] K. S. Rao, S. Anand and P. Venkateswarlu, "Adsorption of Cadmium (II) Ions from Aqueous Solutions by Tectona Grandis L. F. (Teak Leaves Powder)," Bioresources, Vol. 5, No. 1, 2010, pp. 438-454.

[21] Y. Ho and G. McKay, "Sorption of Dyes and Copper Ion 
onto Biosorbents," Process Biochemistry, Vol. 33, No. 7, 2003, pp. 1047-1061. doi:10.1016/S0032-9592(02)00239-X

[22] F. A. Abu Al-Rub, M. H El-Naas, F. Benyahia and I. Ashour, "Biosorption of Nickel on Blank Alginate Beads, Free and Immobilized Algal Cells," Process Biochemistry, Vol. 39, No. 11, 2004, pp. 1767-1773. doi:10.1016/i.procbio.2003.08.002

[23] P. R. Puranik and K. Mpaknikar, "Biosorption of Lead, Cadmium and Zinc by Citrobacter Strain," Biotechnology Process, Vol. 15, No. 2. 1999, pp. 228-237. doi:10.1021/bp990002r

[24] V. B. Saradhii, S. R. K. Rao, P. Y. Kumar, K. Kumaraswamy, B. Sumalatha, A. T. Kumar and G. Kalyani, "Biosorption Studies of Heavy Metal ion on Echinoid," International Journal of Chemical Engineering Research, Vol. 2, No. 2, 2010, pp. 149-157.

[25] S. Al-Asheh and Z. Duvnjak, "Binary Metal Sorption by
Pine Bark: Study of Equilibria and Mechanisms," Separation Science and Technology, Vol. 33, No. 9. 1998, pp 351-368.

[26] U. R. Malik, S. M. Hassany and M. S. Subhani, "Sorptive Potential of Sunflower Stem for Cr (111) ions from Aqueous Solution and Its Kinetics and Thermodynamics Profile," Talanta, Vol. 66, No. 1, 2005, pp. 166-173. doi:10.1016/j.talanta.2004.11.013

[27] I. Villaesusa, N. Fiola, M. Martinez, N. Miralles, J. Poel and J. Serarols, "Removal of Copper \& Nickel Ion from aq. Solution by Grape Stalks Wastes," Water Research, Vol. 38, No. 4, 2004, pp. 992-1002. doi:10.1016/j.watres.2003.10.040

[28] Y. Bulut and Z. Baysal, "Removal of Pb (II) from Wastewater Using Wheat Bran," Journal of Environmental Management, Vol. 78, No. 2, 2006, pp. 107-113. doi:10.1016/j.jenvman.2005.03.010 